\title{
As implicações do internetês na ortografia: um estudo em duas escolas públicas paulistas
}

Anderson Cristiano da Silva ${ }^{1}$

\begin{abstract}
Resumo: Este trabalho discute a presença do Internetês dentro das salas de aula, bem como o impacto que esse fenômeno representa na visão de alunos e professores de escolas públicas nas cidades de São José dos Campos e Taubaté. Além disso, o presente artigo tem como objetivo a reflexão sobre o impacto da linguagem dos internautas em produções de texto de sala de aula, tendo como ponto de partida fundamentos teóricos de gramáticos normativos da Língua Portuguesa e pesquisadores da área, levando-se em consideração os aspectos históricos e contemporâneos. Em termos metodológicos, foram aplicados questionários estruturados em alunos do $9^{\circ}$ ano e de professores de português. Os questionários que foram utilizados para análise embasam nossas conclusões acompanhadas de uma reflexão a respeito da presença do Internetês como uma das novas modalidades de escrita. Nesse sentido, foi problematizada a ideia de como trabalhar com esse desafio em sala de aula, sem violar a língua padrão.
\end{abstract}

Palavras-chave: Ortografia. Internetês. Aprendizado.

\section{IMPLICATIONS OF THE INTERNET SPELLING IN OFFICIAL ORTHOGRAPHY: A STUDY IN TWO PUBLIC SCHOOLS OF SÃO PAULO}

\begin{abstract}
This paper discusses the presence of the internaut language inside the classroom, as well as the impact that it represents in perspective of students and teachers in the public schools of São José dos Campos and Taubaté cities Thus, the present paper aims to reflect about influence of the internaut language in producing texts in the classroom, taking as a starting point the theoretical foundations of the portuguese language grammar normative and researchers of the subject, taking into consideration historical and contemporary. In methodological terms, its structured questionnaires in the 9th grade students and teachers of Portuguese were applied. The questionnaires that have been used for the analysis, base our conclusions followed by a reflection regarding the presence of the internaut language as a new modality of writing. In that sense, was discussed the idea of dealing with this challenge inside the classroom, without violating the standard language.
\end{abstract}

Keywords: Orthography. Internaut language. Learning.

\section{Considerações iniciais}

Esta pesquisa situa-se na área dos estudos gramaticais e tem seu foco na ortografia, especialmente no que diz respeito às implicações ortográficas ocorridas pelo fenômeno contemporâneo denominado Internetês. O que originou o tema gerador da investigação foi a observação de que alguns alunos utilizam abreviações e signos característicos da linguagem virtual nas produções escritas de sala de aula, destoando do que é prescrito pela norma padrão culta. O trabalho focaliza, também, se os docentes conhecem e se têm opiniões formadas sobre esta nova prática de escrita, além de refletir sobre a maneira como os mesmos devem

\footnotetext{
${ }^{1}$ Doutorando em Linguística Aplicada e Estudos da Linguagem (2012-2015) pela Pontifícia Uni Católica de São Paulo (PUC/SP). andcs23@ig.com.br
} 
trabalhar essa nova abordagem com os educandos para que ela não interfira na língua padrão que é ensinada nas escolas regulares de ensino básico.

Em termos metodológicos, o trabalho se desenvolveu por meio de duas etapas. Primeiramente, pesquisa e leitura bibliográfica sobre o assunto em livros, gramáticas, revistas especializadas. Em um segundo momento, elaboramos questionários estruturados para que professores de Português e alunos pudessem responder algumas perguntas relacionadas à internet e ao uso e reconhecimento do Internetês. Após a aplicação dos questionários, foram feitas a análise e a discussão dos resultados como forma de dar uma amostragem da realidade a respeito do Internetês, no ponto de vista dos alunos e educadores de duas escolas públicas paulistas situadas no Vale do Paraíba.

\subsection{Breve histórico sobre a ortografia da língua portuguesa}

A presente seção tratará, de maneira breve, a questão da ortografia, especialmente em perspectiva histórica. Para tanto, serão desenvolvidas a conceituação de ortografia e sua evolução até a contemporaneidade. Ademais, analisaremos como alguns gramáticos tratam desse tema em suas obras, fazendo uma análise contrastiva.

A ortografia é uma estrutura relativamente nova. Em comparação, o francês e o espanhol, por exemplo, eram línguas que há 300 anos não tinham ortografia; o caso da língua portuguesa ainda é mais recente, somente no século XX se estabeleceram as regras no Brasil e em Portugal.

Conforme o dicionário Houaiss (2001), define-se a palavra ortografia como conjunto de regras estabelecidas pela gramática normativa e que ensinam a grafia correta das palavras. Além da definição de ortografia apresentada, é fundamental para a nossa investigação um aprofundamento sobre a evolução histórica da ortografia da língua portuguesa. De acordo com Coutinho (1974), a ortografia portuguesa nunca foi uniforme.

O Renascimento trouxe maior conhecimento do Latim que proclamava que se conhecessem os autores clássicos, romanos e gregos, foi causa de que começassem a aparecer entre nós às complicações gráficas e, por isso, as palavras escritas passaram a sofrer, a partir de então, a influência etimológica, apresentando indumentária mais rica de letras, em flagrante contraste com a primitiva simplicidade (COUTINHO, 1974, p.71).

Segundo os estudos de Coutinho (op. cit.), tais complicações podem ser melheres(3) compreendidas pelo estudo da história da ortografia portuguesa que nos revela de qual maneira houve o distanciamento entre aquilo que se fala e aquilo que se escreve. De acordo 
com o estudioso, a história da ortografia pode ser dividida em três grandes períodos: o fonético, o pseudo-etimológico e o simplificado.

O período fonético começa com os primeiros documentos redigidos em português e se estende até o século XVI, coincidindo com a fase arcaica do idioma (COUTINHO, 1974). Não havia um padrão uniforme na transcrição das palavras, às vezes, num mesmo documento, apareciam os mesmos vocábulos grafados de modo diferente, pois se escrevia não para a vista, mas para o ouvido.

O período denominado de pseudo-etimológico iniciou-se no século XVI e foi até o ano de 1904. O que caracterizou este período foi o emprego de consoantes geminadas e insonoras, de grupos consonantais impropriamente chamados gregos, de letras com o Y, R e W, sempre que ocorriam nas palavras originárias. Coutinho (1974) explicita que o sistema pseudo-etimológico assinalou o divórcio entre a língua escrita e a falada, porém acabou suplantado, isso porque, além de anacrônico, exigia do escriba conhecimento de vários idiomas e não era eficiente, uma vez que há palavras cuja etimologia se ignorava ou para as quais eram propostas várias origens.

Por fim, o período simplificado foi o período em que começaram as reformas ortográficas, buscando simplificar a ortografia do português. A grande inovação desse sistema foi agregar características positivas dos dois sistemas anteriores. Com o fonético, orienta-se pela pronúncia, porém, sem exageros, não descuida da etimologia e do elemento histórico.

Compreendido minimamente uma visão sobre o conceito e o percurso histórico da ortografia em língua portuguesa, acreditamos ser pertinente uma apresentação contrastiva de como alguns renomados gramáticos tratam do assunto em seus compêndios. Para tanto, elencamos três gramáticas: Novíssima Gramática da Língua Portuguesa (CEGALLA, 2000), Nova Gramática do Português Contemporâneo (CUNHA; CINTRA, 2001) e Gramática Normativa da Língua Portuguesa (ROCHA LIMA, 1985).

\subsection{Visões contrastivas sobre a ortografia em gramáticas contemporâneas}

Cegalla (2000), em sua obra, define ortografia como parte da gramática que trata do emprego correto das letras e dos sinais gráficos na língua escrita. Também afirma que o sistema ortográfico, atualmente em vigor, possui as seguintes características:

$1^{\text {a) }}$ É simplificado. Reduziu, por exemplo, consoantes dobradas ou insonoras: ofício, em vez de officio, atento, por attento, salmo, em vez de 
psalmo; aboliu os símbolos gregos: farmácia, em lugar de pharmacia, química, em vez de chimica, teatro, rinoceronte, mártir, em vez de theatro, rhinoceronte, martyr, etc.

$\left.2^{a}\right)$ É científico, pois se baseia na etimologia e segue rígido critério histórico. Por exemplo, rs (latim), ss (português): perscicum - pêssego (e não pêcego).

$3^{\text {a) }}$ É sistemático no uso dos acentos gráficos. Por exemplo, o ditongo oi, quando aberto e tônico, é sempre acentuado: jibóia, eu apóio, etc. (CEGALLA, op. cit., p.52).

Analisando outros dois importantes gramáticos, verificamos que Cunha e Cintra (2001) e Rocha Lima (1985) têm em suas obras um capítulo específico para ortografia, mas não a definem. As gramáticas apresentam notações básicas como: o acento, o til, o trema, o apóstrofo, a cedilha, o hífen e o emprego de algumas letras.

Em suas observações Cunha e Cintra (2001) expõem regras e diferenças de uso das notações léxicas adotadas no Brasil e em Portugal. Além das observações trazidas pelos autores, também mencionam as diferenças entre os sistemas ortográficos oficialmente adotados nos dois países. Por sua vez, Rocha Lima (1985) destina dentro da parte de Fonética e Fonologia um capítulo reservado à ortografia. O capítulo traz uma introdução da periodização da história da ortografia portuguesa (período fonético, período pseudoetimológico e período histórico científico, além de uma síntese didática do sistema ortográfico oficial. Ele destaca no capítulo as generalidades como: o emprego de determinadas letras, consoantes mudas e dobradas, dígrafos, separação de sílabas e acentuação gráfica.

As gramáticas analisadas não apresentam nenhum tipo de exercício relacionado ao tema abordado, apenas definições, instruções, observações e exemplos. Dessa forma, cabe ao professor aprofundar sobre esse conteúdo com seus alunos por meio de atividades complementares retiradas dos livros didáticos ou de outros tipos de materiais didáticos. Ademais, como esses materiais são essencialmente normativos, os casos que destoam das regras e do uso considerado adequado precisarão ser explicitados aos alunos por meio de exemplos e atividades relacionados aos fatos do cotidiano, como por exemplo, a influência do meio virtual na escrita.

Dessa forma, a próxima seção tratará da questão da influência da internet na educação, particularmente no aprendizado da ortografia. Como base, colocaremos em discussão o conceito de internet para que possamos analisar os muitos modos de sua utilização, pois especificamente falaremos sobre os chats. 


\section{A relação entre a internet e o aprendizado de ortografia}

O computador está presente na vida de muitas pessoas e também nas atividades escolares. Dessa forma, o mesmo deve ser utilizado como recurso a mais na produção do conhecimento. Os próprios PCN (BRASIL, 2001) destinam um item específico comentando esta importante ferramenta, que se tornou aliada no ensino da língua, porém nos adverte de maneira a discernir a melhor forma de usá-la. O documento também aborda a interferência do uso do computador na educação brasileira, pois, hoje em dia, já não se fala em escrever um trabalho, mas sim, digitá-lo. Até mesmo em escolas públicas de Ensino Fundamental, esta prática já vem se tornando bastante comum. Com a popularização do computador e o aumento de usuários na internet, a língua vem sofrendo grandes e rápidas transformações, principalmente entre adolescentes e jovens.

A Internet chegou ao Brasil em 1995, aproximadamente (CAMPOS, 2000). Desde então, com o aumento do acesso aos microcomputadores nas residências, a rede começou a se espalhar e, hoje, já envolve certamente alguns milhões de usuários. É por intermédio da Internet que podem ser obtidas as mais diversas informações, pelo sistema World Wide Web. São milhões de sites e homepages que trazem informações sobre os mais variados assuntos, entre outros usos, e é também por meio da Internet que podem ser realizados os chats.

Conforme Campos (2000), chat vem do inglês e significa bate papo, conversar, fofocar. Um chat, em jargão internauta, significa um lugar virtual em que diversas pessoas podem se encontrar on-line, para conversar sobre os mais variados temas. A conversa acontece praticamente em tempo real, ou seja: alguém digita uma mensagem e a envia por meio do computador. Em uma sequência imediata, outra pessoa recebe a mensagem do "outro lado" podendo ler e responder a mensagem, dentro da mesma continuidade.

O chat vem fazendo parte da vida de um número cada vez maior de pessoas. Com o uso dos chats, também houve um surgimento de uma modalidade diferente de escrita, própria dos usuários, que foi denominada de Internetês.

Para compreender este fenômeno do Internetês, é preciso, segundo Costa e Freitas (2005), entender a presença entre nós desta nova tecnologia, a Internet. É preciso pensá-la numa perspectiva histórica, analisando o surgimento da escrita com o surgimento da informática. Outro parâmetro importante, para a concepção do Internetês, é a relação com a linguagem oral, pois a maioria das características do pensamento e da expressão fundadas no oral é relacionada com a interiorização do som (COSTA; FREITAS, 2005). As palavras 
pronunciadas são ouvidas e internalizadas; com a escrita, precisa-se de um outro sentido: a visão. As palavras não mais são ouvidas, mas vistas, entretanto, o que se vê não são as palavras reais, mas símbolos codificados, que evocam na consciência do leitor palavras reais, o som se reduz ao registro escrito.

De acordo com Possenti (2006), a identidade da língua é, por razões que até hoje não são completamente claras, relacionada à escrita. A abordagem dessa questão nos remete à grafia correta das palavras que tanto nos faz refletir sobre a influência ou não do Internetês na norma culta. A questão é relevante, especialmente, porque diz respeito ao encontro de um meio extremamente contemporâneo, que é a internet, com um instrumento tão antigo como a escrita. Para Possenti (2006), a maneira como os adolescentes escrevem deveriam ser um lugar no qual as pessoas que estudam a língua pudessem aprender e não, simplesmente, motivo de críticas por parte de alguns puristas da língua. O estudioso discorre sobre a importância de antes de criticarmos qualquer variação da língua, conhecermos o fenômeno sem nenhum tipo de pré-conceito, para isso precisamos conhecer o tema discutido.

Para alguns professores, o Internetês compromete o aprendizado da língua portuguesa padrão. No entanto, outros veem a chegada do Internetês com mais naturalidade e dizem que toda forma de comunicação é válida, com a ressalva de que é preciso que os alunos estejam atentos para que a linguagem virtual não extrapole situações que exigem o uso do português padrão culto. Por isso, há necessidade de que os docentes tomem consciência e aprendam a trabalhar com esta realidade, com devidos cuidados, para que os alunos, ainda que navegando na rede, não sejam prejudicados na aprendizagem da língua materna e aprendam a ter senso crítico ao escrever.

O Internetês é um assunto recente e polêmico do qual há muito a se explorar. Segundo Karla Hansem (2006), devemos seguir o exemplo, de alguns professores de língua portuguesa que já tiveram a iniciativa de promover, em sala de aula, atividades sobre o Internetês. Não se trata de rejeitar, diminuindo-lhe a importância ou de elevá-lo aos céus, atribuindo-lhe poderes de revolucionar ou mesmo ameaçar a língua portuguesa. Essas experiências em sala de aula têm a qualidade de reconhecer o fenômeno e explorá-lo, mostrando sua dimensão real.

Hamze (2006) assevera sobre a importância do papel do educador: que é de preparara(3) o educando para o uso crítico das diversas formas de linguagem e também sua utilização forma adequada. Com a popularização da informática, o Internetês tornou-se um fenôneno 
que veio para ficar. Não podemos, como educadores, ignorar ou agir de forma preconceituosa sobre este novo tipo de linguagem. Ademais, Marcuschi (2002) considera que a presença do computador na escola seja uma realidade da qual não podemos fugir e que o uso do computador está se tornando cada vez mais corriqueiro até mesmo nas escolas públicas. Ao mesmo tempo, comenta que existem poucas reflexões críticas a respeito do uso da computação em sala de aula e que esse uso vem ocorrendo de modo ingênuo e despreparado.

A invasão de certos termos e expressões próprios da Internet nas redações escolares tem suscitado um debate nem sempre consensual a respeito da influência da linguagem virtual na produção escrita de alunos do ensino fundamental. Há estudiosos que acreditam que essa invasão pode prejudicar o desempenho dos estudantes e contribuir para o empobrecimento da língua. Outros, no entanto, defendem a tese de que tal preocupação não tem fundamento, uma vez que, é próprio de todas as línguas, se transformarem com o passar do tempo e adquirirem novos valores sociolinguísticos, sem, contudo, se degenerarem ou se tornarem imperfeitas.

Grespan (2005) é um dos defensores dessa linha. Em seu trabalho intitulado $O$ uso da Língua Portuguesa escrita em tempo real na internet, afirma que a internet só veio valorizar a língua escrita, já que antes dela poucas pessoas usavam a língua escrita com tanta frequência em seu cotidiano. Para o autor, as abreviações e símbolos usados nas salas de bate-papo têm como objetivo tornar a comunicação mais ágil e informal, uma vez que os interlocutores não dispõem de tempo para fazer um planejamento prévio de seu discurso.

Segundo o estudioso, é o planejamento que torna a linguagem das salas de bate-papo tão parecida com a língua falada informal, uma vez que em ambas as situações o planejamento é local, ou seja, vai sendo construído conforme os interlocutores trocam os papéis na conversa. Outro aspecto bastante interessante é que, em sua conclusão, Grespan (2005) defende a tese de que, a despeito de alguns internautas viciados usarem essa linguagem em situações em que se exige o emprego da norma culta, a linguagem do mundo virtual provavelmente jamais invadirá o mundo real, pois a língua utilizada pelos internautas, salvo algumas exceções, não teria uma utilidade prática no mundo real, dado que a língua escrita exige uma precisão que a linguagem hermética dos internautas não tem.

Concluímos que ainda não há um consenso sobre a temática, pois faltam informações e pesquisas sobre o tema para se saber se realmente o Internetês será um grande influenciador na escrita formal ou será apenas mais uma maneira de comunicação própria de um ambiente específico. Para tanto, no próximo capítulo tentaremos analisar alguns dados sobre o assunto 
por meio de uma pesquisa sobre o tema realizada em duas cidades paulistas: São José dos Campos e Taubaté. Ambas estão localizadas no Vale do Paraíba, região cortada pela via Dutra, ligando o principal eixo econômico do país (Rio - São Paulo).

\section{Análise dos resultados: a visão de alunos e professores sobre o Internetês}

A pesquisa realizada entre alunos do $9^{\circ}$ ano ( $8^{\mathrm{a}}$ série) de escolas públicas e professores de língua portuguesa teve como finalidade observar a situação da influência do Internetês e suas implicações na visão de discentes e docentes. O conteúdo dos questionários dos teve questões objetivas, com respostas estruturadas, conforme observamos abaixo:

Quadro 1 - Modelo de questionários utilizados para os alunos e professores

\begin{tabular}{|c|c|}
\hline QUESTIONÁRIOS DOS ALUNOS & QUESTIONÁRIO DOS PROFESSORES \\
\hline $\begin{array}{l}1 \text { - Você tem computador e utiliza internet em } \\
\text { casa? } \\
\text { ( ) Sim ( ) Não } \\
2 \text { - Você costuma entrar nas salas de bate-papo } \\
\text { com frequência? } \\
\text { ( ) Sim ( ) Não } \\
3 \text { - Você consegue reescrever a frase abaixo, } \\
\text { utilizando a norma culta padrão? Caso } \\
\text { afirmativo, dê a respota. } \\
\text { Kd } v c k \text { naum dexo coments no meo flog pra eu } \\
\text { fla ctg? } \\
\text { ( ) Sim ( ) Não } \\
\text { Resposta: } \\
4 \text { - Você considera prejudicial essa forma de } \\
\text { escrita dentro da sala de aula? } \\
\text { ( ) Sim ( ) Não }\end{array}$ & $\begin{array}{l}\text { 1-Você sabe o que é "Internetês"? } \\
\text { ( ) Sim ( ) Não } \\
2 \text { - Costuma utilizar a internet para complementar } \\
\text { suas aulas? } \\
\text { ( ) Sim () Não } \\
3 \text { - Você costuma entrar nas salas de bate-papo? } \\
\text { ( ) Sim ( ) Não } \\
4 \text { - Você utiliza a linguagem praticada pelos } \\
\text { internautas? } \\
\text { ( ) Sim ( ) Não } \\
5 \text { - Você consegue traduzir esta frase do } \\
\text { Internetês? } \\
\text { (Kd vc k naum dexo coments no meo flog pra eu } \\
\text { fla ctg?) } \\
\text { ( ) Completamente ( ) Parcialmente) ( ) Nada } \\
\text { 6- Você acredita que este tipo de linguagem irá } \\
\text { prejudicar as produções de texto dentro da sala de } \\
\text { aula? } \\
\text { () Sim ( ) Não }\end{array}$ \\
\hline
\end{tabular}

A pesquisa de campo foi realizada em duas escolas municipais de Ensino Fundamental: EMEF Prof ${ }^{a}$ Silvana Maria Ribeiro de Almeida, situada no município de São José dos Campos, e EMIEF Marta Miranda DEl Rei, localizada em Taubaté. Para nossas 
análises, dividimos em dois momentos. No primeiro, concentramos as discussões nos resultados das repostas dos alunos, para o segundo momento, refletimos sobre as respostas dos professores de língua materna. Dessa forma, segue na sequência o primeiro gráfico com a sistematização das repostas dos alunos

Fig. 1 - Resposta dos alunos

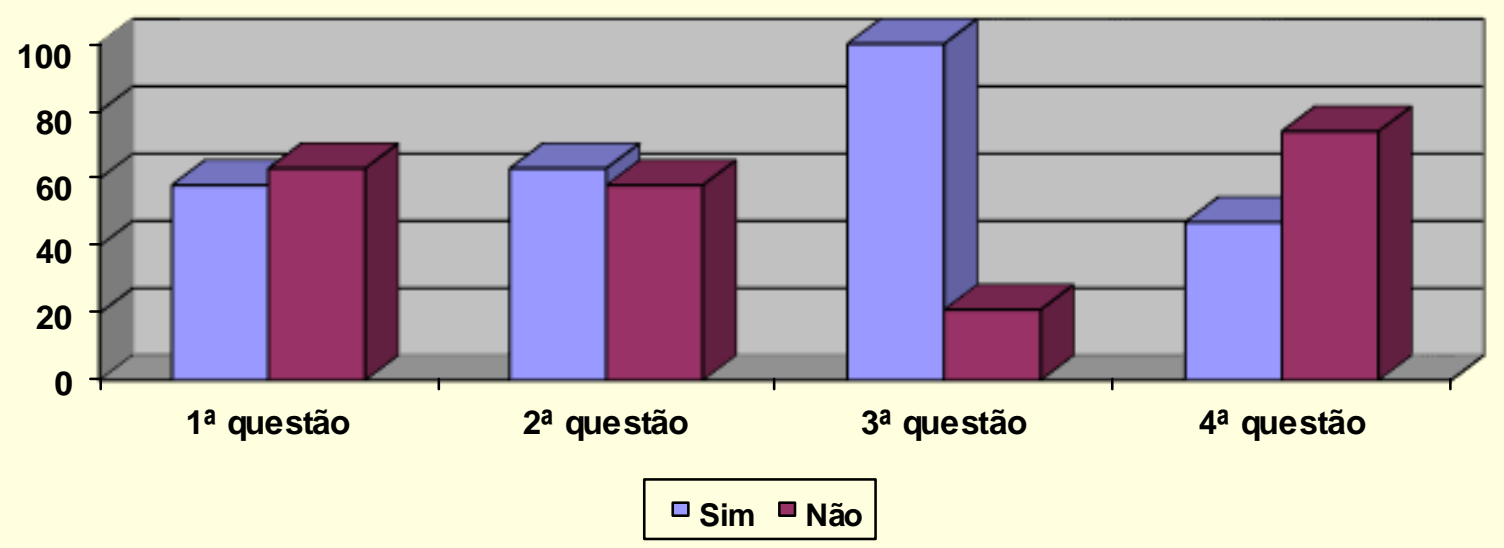

A primeira questão objetivou verificar o número de alunos que possuem computador e que o utilizam em suas casas. A partir dos dados coletados, constatamos que $48 \%$ dos alunos envolvidos na pesquisa têm computador em casa e utilizam a internet, porém $52 \%$ dos alunos não possuem. Esse resultado aponta questões relacionadas à condição socioeconômica dos educandos, pois mesmo as escolas estando situadas em uma das principais regiões econômicas do país, a localização em determinado bairro pode influenciar nos resultados, conforme o poder aquisitivo da comunidade escolar.

A segunda pergunta verificou se frequentemente os alunos entram nas salas de batepapo. Os resultados coletados mostraram que 52\% dos que usam internet entram nos chats com frequência e $48 \%$ não. Esse aponta o resultado da popularização da internet e o aumento das redes sociais, que acabou diluindo o número de usuários de chat, fazendo-os migrar para outros meios de comunicação on-line, como: Facebook, Skype, Whatsapp, Instagram. Além disso, as respostas, também indiretamente, remetem à rapidez em que esses novos meios de comunicação acabam disputando usuários, como foi o caso, por exemplo, do Orkut para o Facebook. Desse modo, mesmo com a inserção de inúmeros aplicativos de interação, os chats continuam sendo utilizados numa proporção expressiva. 
A terceira questão vislumbrou observar se os alunos seriam capazes de reescrever uma frase do Internetês para a norma culta. Do total de pesquisados, $83 \%$ responderam sim e $17 \%$ não. O resultado comprovou que a maior parte dos educandos pesquisados conhece e sabe interpretar o Internetês. A questão pesquisada tinha a seguinte frase: $K d v c k$ naum coments no meo flog pra eu fla ctg? (Cadê você que não deixou um comentário na minha página pessoal de fotos para eu falar contigo?). Essa modalidade de escrita revela uma característica, como a predominância de consoantes nas abreviações em detrimento das vogais. Além disso, como já mencionado em nosso artigo, essa forma compactada de escrita no meio virtual não é algo arbitrário, mas possui regularidades que permitem aos usuários compreenderem esse tipo de escrita, que se justifica pela necessidade de tornar mais dinâmico o processo de interação escrita, tentando igualar-se ao processo oral.

$\mathrm{Na}$ última questão, fizemos a seguinte pergunta: Você considera prejudicial esta forma de escrita (Internetês) dentro da sala de aula? A maior parte dos pesquisados (61\%) considera que não seja prejudicial (sendo que 39\% considera que sim). Temos que levar em consideração a maturidade dos pesquisados, pois nesta faixa etária, alguns ainda não adquiriram uma consciência crítica para argumentar se determinado fato da língua é prejudicial ou não, bem como as implicações e influência sobre fenômenos da internet na escrita formal padrão. A diferença entre as porcentagens mostra uma parcela considerável de alunos preocupados com os aspectos negativos que o Internetês pode causar. Embora ainda não haja pesquisas em quantidade expressiva que comprovem essa posição, o simples fato de $39 \%$ dos educandos estarem preocupados com a possível influência desse fenômeno já indica um aspecto positivo.

Dando continuidade as nossas análises, segue abaixo o segundo gráfico, sistematizando os resultados das respostas por professores de Língua Portuguesa. Para a constituição do corpus, foram utilizadas as respostas de todos os professores de Língua $\left.\begin{array}{lllll}\text { Portuguesa } & (\mathrm{EF} \quad \mathrm{e} & \mathrm{EM}\end{array}\right)$ das escolas supracitadas. 
Fig. 2 - Resposta dos professores



$\square$ Sim $\square$ Não $\square$ Completamente $\square$ Parcialmente $\square$ Nada

A primeira questão objetivou verificar se os professores conheciam o termo Internetês, $89 \%$ afirmaram positivamente e $11 \%$ responderam que não conheciam o vocábulo. A porcentagem expressiva de docentes que conhecem o vocábulo Internetês aponta que grande parte parece possuir consciência dos novos fenômenos da linguagem, principalmente os oriundos do meio virtual, o que comprova que esses profissionais mantêm-se atualizados.

O objetivo da segunda questão era saber se os professores costumam utilizar a internet para complementar suas aulas, 67\% responderam sim e 33\% não. Com esse resultado, mesmo com a popularização da internet, uma quantidade considerável ainda não usa os recursos do meio virtual para complementação de suas aulas. Essa porcentagem faz relação com outro assunto: a questão da formação docente de professores de língua. Desse modo, as respostas engendradas nessa pesquisa também podem ser um reflexo do que acontece atualmente, pois vivemos um momento de transição em que docentes de diferentes gerações atuam no ensino de língua. Assim, muitos professores mais experientes não tiveram uma formação pessoal e profissional com relação ao computador, o que ressoa também no grau de familiaridade e regularidade em que esses profissionais utilizam a internet para complementar as aulas. Por sua vez, também há os novos professores que compreendem uma geração que cresceu com a presença dos computadores/internet em seus lares, o que também refletirá no domínio das novas ferramentas virtuais em suas atuações como educadores de língua.

Perguntamos na questão número três se os docentes entravam nas salas de bate-papo. Todos os entrevistados disseram não. Tal fato mostra que, diferentemente dos alunos, pelo 
menos os docentes pesquisados não se comunicam por meio dos chats, o que podemos inferir que esses professores devem utilizar outras ferramentas de comunicação, como os diversos aplicativos existentes nos celulares.

A questão quatro está estritamente ligada à questão anterior, como não costumam utilizar os chats, os mesmos disseram que não utilizam esse tipo de linguagem própria do meio virtual. Ademais, essa unanimidade (d)enuncia uma espécie de ethos dos docentes, ou seja, a representação de si no discurso. Assim, os professores de língua tentam se policiar nas diferentes esferas para escrever o mais próximo possível da norma culta padrão, pois têm consciência que são exemplos para seus alunos e pessoas próximas, por isso são mais cobrados pela sociedade, exigindo que tais profissionais não errem nunca, o que pode nos remeter a outras discussões que não cabem neste artigo.

Na quinta questão fizemos a seguinte pergunta: Você consegue traduzir esta frase do Internetês: "Kd vc k naum coments no meo flog pra eu fla ctg?" Dos professores pesquisados, $22 \%$ responderam que conseguem compreender completamente, $72 \%$ parcialmente e $6 \%$ nada. Em consonância com tal resultado, recorremos a opinião de um estudioso da temática. De acordo com Silva (2003), as questões referentes à leitura na Internet devem ser direcionadas para um contexto mais amplo. As reflexões devem ser direcionadas para dois componentes básicos: (1) o acesso à informação e à produção do saber, assim entendidos como instrumentos básicos de trabalho, desenvolvimento social e participação política; e (2) o domínio, de competências capazes de possibilitar práticas de leitura e de letramento. A produção e a circulação de textos virtuais trazem desafios para a educação formal das novas gerações, ainda que esses textos sejam produzidos por meio da esfera virtual, eles se apresentam dentro de um suporte específico e adquirem configurações únicas, resultando em mais atitudes e comportamentos de leitura do texto virtual.

A última questão apresentada aos docentes foi: Você acredita que este tipo de linguagem irá prejudicar as produções de texto dentro da sala de aula? Dos entrevistados, $83 \%$ responderam que sim e $17 \%$ que não. De acordo com as respostas obtidas dos alunos e professores sobre a influência do Internetês em sala de aula, observamos que a maioria acredita que o Internetês não prejudica a escrita em sala de aula. Porém, os professores revelaram uma visão diferente, pois pressupõem que a linguagem do Internetês pode prejudicar a linguagem formal ensinada em sala de aula. 
O resultado contrastivo entre o poder de compreensão de alunos e docentes sobre o Internetês revela a necessidade dos professores compreenderem cada vez mais os fenômenos da linguagem que surgem no meio virtual, pois podem implicar na aprendizagem da língua materna e nas suas várias modalidades.

\section{Considerações finais}

No mundo virtual, a comunicação falada, escrita e/ou lida é horizontal, livre e democrática: talvez resida nisso a possibilidade maior de instauração de um certo tipo de cultura entre os homens que, pelas práticas de leitura - aqui tomadas como uma atividade estruturante do pensamento - poderão, de agora em diante, viver mais intensamente a criatividade e a liberdade.

Essas inovações chamam a atenção de estudiosos, que temem a "contaminação" da língua portuguesa e prejuízos para o seu aprendizado. Santos (2003 apud BRITO, 2005) estudou o uso desses programas e acabou concluindo que o hábito de utilizar expressões do meio virtual não influencia negativamente a escrita do adolescente. Em sua pesquisa, que levantou dados de jovens usuários da internet, procurou descrever sua utilização, coletando amostras da interação on-line e as comparou à escrita de outros gêneros desses mesmos estudantes, como cartas, provas e também bilhetes que, sem o conhecimento do professor, circulam em sala de aula. Segundo a autora, a análise dos dados revelou que a linguagem usada nos chats é influenciada pelo suporte - o computador -, e que o adolescente pesquisado sabe adequar a sua linguagem a diferentes gêneros, em diferentes situações de comunicação.

O surgimento do Internetês, trouxe em pauta à discussão sobre a influência negativa desse fenômeno na já fragilizada aprendizagem da escrita correta da língua. Nesse sentido, o Internetês é um assunto que ainda divide opiniões. Considerando que o sentido literal de ortografia é a escrita correta das palavras e seu aceitamento é unânime entre os escolarizados, o que constatamos foi que o espaço destinado ao Internetês é ínfimo.

Pelo que observamos, o Internetês é mais uma maneira de expressão no meio virtual, com a utilização de determinados símbolos combinatórios, característicos dessa modalidade escrita, que tenta reproduzir a velocidade do diálogo em tempo real. Assim, a internet cria 
uma espécie de revolução, pois os (inter)locutores podem trocar informações com o mundo todo numa velocidade instantânea.

Com a pesquisa, concluímos que entre os educandos das escolas públicas municipais situadas em periferia, a influência do Internetês na ortografia da língua materna ainda não é acentuada e muitos acreditam não ser prejudicial esta forma de escrita dentro da sala de aula, já os educadores consideram prejudicial, sim, o Internetês nas produções escritas dos educandos, mas alguns pesquisadores acreditam que conhecer mais de uma modalidade de escrita é positivo, desde que os alunos usem o bom senso na sua utilização, conforme a situação e esferas envolvidas.

Dessa forma, caberá aos professores de língua portuguesa se aprofundarem na temática, para que possam criar estratégias de ensino eficazes sobre a ortografia, bem como atividades em que os educandos possam refletir criticamente e discernir sobre a utilização do Internetês e suas implicações nas diferentes esferas.

\section{Referências}

BRASIL. MINISTÉRIO DE EDUCAÇÃO E CULTURA. Parâmetros Curriculares Nacionais de Língua Portuguesa. Brasília: MEC/ SEMTEC, 2001.

BRITO, P. Um tiro no escuro: as estratégias e incertezas da inclusão digital no Brasil. 107f. Dissertação (Mestrado em Língua Portuguesa) - Programa de Pós-graduação em Língua Portuguesa, Pontifícia Universidade Católica de São Paulo, São Paulo, 2005.

CAMPOS, I. F. Tudo o que você queria saber sobre as salas de chat (bate papo) e não tinha a quem perguntar. In: Boletim Clínico, n.08maio/2000. Disponível em: <http://www.pucsp.br/clinica/boletim08_03.htm>. Acesso em 01 jan. 2006.

CEgAllA, D. P. Novíssima Gramática da Língua Portuguesa. 43. ed. São Paulo: Companhia Editora Nacional, 2000.

COUTINHO, I. de L. A ortografia portuguesa. In: Pontos de Gramática Histórica. 6. ed. ver. Rio de Janeiro: Livraria Acadêmica, 1974.

CUNHA, C.; CINTRA, L. F. L. Nova Gramática do Português Contemporâneo. 2. ed. Rio de Janeiro. Editora Nova Fronteira S.A, 1985.

FREITAS, M. T. de A; COSTA, S. R. (Org.). Leitura e escrita de adolescentes na internet e na escola. Belo Horizonte: Autêntica, 2005. 
GRESPAN, G. Pesquisa Uso da Língua Portuguesa Escrita em Tempo Real na Internet. Disponível em: 〈http://br.altavista.com/web/default/ortografia nos chats $>$ ou 〈http:www.gilmar-homepage.hpg.ig.com.br>. Acesso em: 07 nov. 2005.

HAMZE, A. "Internetês": aqui vira "aki", não é "naum" e beleza é bl”. Disponível em <www.pedagogia.brasilescola.com/internetes.html>. Acesso em: 06 jan. 2006.

HOUAISS, A. Dicionário Houaiss da Língua Portuguesa. Rio de Janeiro: Objetiva, 2001.

MARCURSCHI, L. A. Gêneros textuais e ensino. Rio de Janeiro: Lucerna, 2002.

POSSENTI, S. Você Entende Internetês? In: Discutindo Língua Portuguesa. Ano 1. n. 2. p. 28 - 33. São Paulo: Editora Escala Educacional, 2006.

ROCHA LIMA, C. H. da. Gramática normativa da língua portuguesa. 25 ed. Rio de Janeiro: José Olympio, 1985.

SILVA, E. T. da et alli. A Leitura nos Oceanos da Internet. São Paulo: Editora Cortez, 2003.

Recebido em 06 de julho de 2014 Aceito para publicação em 17 de agosto de 2014 